\title{
O documento como fonte primária nos estudos da enfermagem e da saúde: uma reflexão
}

The document as a primary source in nursing and health studies: a reflection El documento como fuente primaria en los estudios de enfermería y salud: una reflexión

\author{
Djailson José Delgado Carlos ${ }^{1}$ (1) \\ Maria Lígia dos Reis Bellaguarda² (1) \\ Maria Itayra Padilha² (D)
}

1. Universidade Federal do Rio Grande do Norte, Hospital Universitário Onofre Lopes. Natal, RN, Brasil.

2. Universidade Federal de Santa Catarina, Programa de Pós-Graduação em Enfermagem. Florianópolis, SC, Brasil.
Autor correspondente:

Djailson José Delgado Carlos.

E-mail: djailson.delgado@hotmail.com

Recebido em 10/08/2021.

Aprovado em 13/09/2021.

DOI:https://doi.org/10.1590/2177-9465-EAN-2021-0312

\section{RESUMO}

Objetivo: analisar as interfaces e distinções histórico-conceituais acerca dos estudos documentais, enquanto método de pesquisa, na área da Enfermagem e da saúde. Método: ensaio teórico de cunho reflexivo, elaborado com base na literatura nacional e internacional sobre o tema. Resultados: apresenta uma teorização acerca da evolução conceitual dos documentos e as contribuições advindas da Escola de Annales, com ênfase na expansão documental, também referida como revolução. Fundamenta conceitos, organização, coleta e análise dos dados documentais e as relações com a pesquisa histórica aplicada à Enfermagem e, por conseguinte, à saúde. Aborda a produção do conhecimento como parte do desenvolvimento da educação e da pesquisa em Enfermagem, no Brasil. Conclusões e implicações para a prática: a apropriação das fontes documentais e dos métodos no desenvolvimento da pesquisa, do ensino e da assistência à saúde aguçam a curiosidade e ampliam a capacidade de análise, de crítica e de autonomia de grupos de interesse e estudiosos, esperando-se, com isso, a ampliação do conhecimento relacionado à profissão.

Palavras-chave: Enfermagem; Grupos de pesquisa; História; Métodos; Pesquisa.

\begin{abstract}
Objective: to analyze the historical-conceptual interfaces and distinctions regarding documentary studies as a research method in the field of Nursing and health. Method: theoretical essay with a reflective nature based on national and international literature on the subject. Results: the study presents a theorization about the conceptual evolution of documents and the contributions of Annales School, with emphasis on document expansion, also referred to as revolution. It supports concepts, organization, collection and analysis of documentary data and its relationships with historical research applied to Nursing and, therefore, to health. It addresses the production of knowledge as part of the evolution of education and research in Nursing in Brazil. Conclusions and implications for practice: the appropriation of documentary sources and methods in the development of research, teaching and health care sharpens curiosity and expands the capacity for analysis, criticism and autonomy of interest groups and scholars, being expected, with this, the expansion of knowledge related to the profession.
\end{abstract}

Keywords: Nursing; Research groups; History; Methods; Research.

\section{RESUMEN}

Objetivo: analizar las interfaces y distinciones histórico-conceptuales acerca de los estudios documentales cómo método de investigación en el campo de la Enfermería y la salud. Método: ensayo teórico con carácter reflexivo basado en la literatura nacional e internacional sobre el tema. Resultados: presenta una teorización sobre la evolución conceptual de los documentos y los aportes de la Escuela de los Annales con énfasis en la expansión documental. Apoya conceptos, organización, recolección y análisis de datos documentales y sus relaciones con la investigación histórica en Enfermería y, por consiguiente, en salud. Aborda la producción de conocimiento como parte de la evolución de la educación y la investigación en Enfermería en Brasil. Conclusiones e implicaciones para la práctica: la apropiación de fuentes y métodos documentales en el desarrollo de la investigación, la docencia y la salud agudiza la curiosidad y amplía la capacidad de análisis, crítica y autonomía de grupos de interés y académicos.

Palabras clave: Enfermería; Grupos de investigación; Historia; Métodos; Investigación. 


\section{INTRODUÇÃO}

A história não se refere meramente ou exclusivamente ao passado remoto ou recente. Ao contrário, a grande força da história vem da compreensão de que a carregamos conosco, somos inconscientemente controlados por ela de muitas maneiras, e ela está, literalmente, presente em nossas ações e realizações. Portanto, êxitos ou fracassos, acontecimentos em geral que nos ocorrem em diferentes espaços físicos e sociais, são de interesse dos pesquisadores-historiadore ${ }^{a}$ e da sociedade, e servem como propósitos à investigação histórica. Eles escrevem, analisam e interpretam os acontecimentos e, por isso, são frequentemente chamados de "[...] detetives, olhando diferentes pedras para obter pistas, em vez de simplesmente descreverem a aparência e a localização delas [...]"1. A prática da investigação histórica é uma atividade que permite ao pesquisador-historiador voltar às suas raízes, ativar e reativar a memória, se distanciar de possível fragmentação nesse processo de articulação entre o presente e o passado, por meio do elo entre esses dois tempos históricos da atividade humana. Em qualquer tema de pauta, existe uma história prévia, posto que não há identidade se não houver memória ${ }^{2}$. Ou seja, a história é resguardada pela memória escrita, falada, imagética, iconográfica, que permite conhecer e entender os eventos, as pessoas, os lugares, os contextos e as sociedades.

A quebra de paradigmas acerca dos modos de se registrar a história ocorreu a partir da École des Annales, que, ao recomendar aos pesquisadores-historiadores que planejassem seus estudos tornando-os científicos, exerceu influência importante em todo o mundo. Esse movimento, surgido na França, na década de 1920, ganhou notoriedade após a criação e circulação da Revista Annales d'Historie Economique et Sociale, a partir do ano de 1929, idealizada e editada por Lucien Febvre e Marc Bloch. A École des Annales propôs a ampliação do sentido de "documento" para se contar história, reivindicando importância a tudo que pertence e rodeia o homem. Assim, passou a ser denominada de Nova História, trazendo a análise das estruturas sociais, da atividade econômica e dos comportamentos coletivos como objeto de estudo dos pesquisadores-historiadores ${ }^{3}$. Essa abordagem permitiu que a história pudesse ser visualizada sob um novo prisma, em que as atividades humanas e as estruturas sociais, políticas e econômicas, por meio de várias fontes históricas, fossem contextualizadas e compreendidas, superando a simples interpretação da realidade. Nessa concepção, a história era e ainda permanece como a ciência que estuda a evolução das sociedades humanas sem tempo cronológico ${ }^{3,4}$.

Com isso, os pesquisadores-historiadores ampliaram os seus horizontes para além daqueles temas relacionados à história tradicional, passando a pesquisar sobre variados conteúdos-como política e economia -, proporcionando um novo entendimento sobre a história remota e recente, de forma abrangente e diversificada Desse modo, a história dos diferentes grupos sociais - determinantes e condicionantes do processo saúde-doença, características individuais e outros nomes, referentes ao processo de viver humano - tornaram-se foco de estudos.

A partir de 1960, os estudiosos ampliaram mais ainda seu objeto de pesquisa, buscando nos assuntos sociais sua seara de exploração do conhecimento histórico e, com início em 1970, ocorreu a valorização e avanços da investigação histórica na área da saúde, mediante demandas relativas às profissões e construção de memórias coletivas. De 1980 em diante, houve valorização das pesquisas de experiências individuais, impulsionando o estudo da história cultural, social, política e contemporânea. Nesse período, a Enfermagem também passou a investigar mais profundamente sobre suas raízes, investindo em estudos e publicações com abordagem histórica, para a ampliação dos conhecimentos sociais, culturais, políticos, de educação, saúde e gênero ${ }^{5,6}$.

O olhar para a profissão, sob as luzes da Nova História, ampliou as possibilidades de compreender a Enfermagem como parte de um processo histórico, político, educativo, de gênero, analisando e denunciando, de forma contundente, a maneira como a identidade profissional foi sendo construída ao longo dos séculos. Esse movimento crescente, nas últimas décadas, se comprova pelo aumento significativo de produções desenvolvidas por enfermeiras - docentes e assistenciais - que, cientes de suas responsabilidades, compreenderam a necessidade de instrumentalizar, com toda propriedade, seus congêneres, fornecendo elementos que propiciem a compreensão dos determinantes históricos relacionados à prática social da profissão. Essa produção se deve, principalmente, ao incentivo realizado pelos programas de Pós-Graduação em Enfermagem, decorrente da criação e funcionamento dos grupos e laboratórios de pesquisa histórica ${ }^{7}$.

Esses grupos e laboratórios de pesquisa valem-se dos recursos metodológicos oriundos da École des Annales, e fundamentam-se na Nova História, sob a perspectiva contextualizada, reflexiva e crítica dos acontecimentos como resultantes de forças sociopolíticas, reconhecendo o ser humano enquanto protagonista do seu mundo, em sua época. Para esse empenho, interrelacionam saberes acumulados por outras ciências, e trabalham sob a concepção renovada e ampliada das fontes históricas ${ }^{8}$, considerando tudo aquilo que pertence ao humano, depende dele, serve-o, exprimindo e demonstrando sua presença, atividades, gostos e maneiras de ser ${ }^{9}$.

Diante do exposto, essa reflexão resulta de inquietações surgidas entre pesquisadores-historiadores em história da Enfermagem e da saúde, quanto à necessidade de refletir e alinhar conceitos sobre a pesquisa histórica, do tipo documental, com vistas a apoiar sua operacionalização. Assim sendo, para o seu alcance, estabeleceu-se como objetivo analisar as interfaces e distinções histórico-conceituais acerca dos estudos documentais, enquanto método de pesquisa, na área da Enfermagem e da saúde.

\section{MÉTODO}

Trata-se de um manuscrito reflexivo, elaborado a partir da vivência dos autores como pesquisadores-historiadores, e da consulta à literatura disponibilizada pelas bibliotecas eletrônicas e bases de dados, além de livros clássicos sobre o tema e guias do Arquivo Nacional. Destinado a contribuir com elementos para a discussão sobre estudos documentais aplicados à Enfermagem e saúde, encontra-se estruturado de acordo com as seguintes seções: (1) A École des Annales e a expansão documental; (2) 
Documentos: conceito, utilização e características; (3) Documentos: guarda, conservação, manuseio e cuidados; e (4) Pesquisa histórico-documental aplicada à Enfermagem.

\section{RESULTADOS E DISCUSSÃO}

\section{A École des Annales e a expansão documental}

A École des Annales, desde o seu surgimento, vem formando seguidas gerações de pesquisadores-historiadores, que têm impresso novas abrangências à história-problema em distintas vertentes - com particular interesse às questões sociais negligenciadas -, assim como agregado novas fontes históricas e o uso de novos métodos historiográficos ${ }^{3}$.

Corresponde, pois, a uma elaboração contrária à história tradicional, positivista, fundamentada nos textos e nos documentos escritos; por isso, considerada pseudo-história devido a sua abordagem superficial e simplicista dos acontecimentos. Sob a perspectiva de história-problema, inovou quanto às maneiras de ver e de pensar os fatos históricos e por dignificar a multiplicidade de documentos. Por exemplo: escritos de todos os tipos, documentos figurados, mobiliários, jornais, utensílios, achados arqueológicos, atas, relatórios, contratos, vestimentas, entrevistas, signos, discursos, pergaminhos, lápides, paisagens, inventários, dados estatísticos, obras literárias, fósseis, revistas, fotografias, monumentos, ferramentas, esculturas, filmes, peças de cerâmica, registros paroquiais, entre outros ${ }^{8,9}$.

Assim sendo, o Quadro 1 permite a visualização sintética e cronológica do processo de ampliação das fontes históricas, proporcionado a partir da École des Annales.

Essa pluralidade de fontes históricas - textuais e não textuais - têm respaldado a denominada revolução documental ${ }^{9}$ ou expansão documental por corresponder à ampliação quantitativa e qualitativa dos documentos, entendendo que eles não são representantes neutros do passado, visto que resultam da intencionalidade de forças sociais ${ }^{10}$.

Destaca-se que, para a apropriada utilização, o pesquisadorhistoriador realiza a análise contextualizada das diversas fontes localizadas, por mais complexas que sejam, sem perder o foco de que derivam de um passado social. Por isso, devem ser meticulosamente, examinadas em suas peculiaridades temporais. Espera-se que esse grandioso desafio o mantenha estimulado a realizar novas buscas, visando complementar as informações, e a transformá-las em conhecimento meritório a partir de fontes históricas confiáveis.

A ampliação das fontes históricas documentais possibilita o exame e reexame dos diversos materiais, além de novas interpretações ou o acréscimo de versões complementares aos fenômenos. Esse panorama se deve, também, à sua utilização por pesquisadores-historiadores, a saber: antropólogos, profissionais da educação e saúde, sociólogos, religiosos, cientistas políticos, economistas, literários ${ }^{11}$. Essa realidade faz perceber a pesquisa documental como um campo fértil, com muitas possibilidades, e, por isso, correlativa a muitas áreas do conhecimento.

\section{Documentos: conceito, utilização e características}

Definir o documento representa em sium grande desafio, sendo a História, dentre todas as Ciências Sociais, a que atribuiu mais importância à utilização dessa ferramenta ${ }^{12}$. Quanto a isso, tudo o que é vestígio do passado ou serve de testemunho, é considerado documento ou fonte, podendo se tratar de textos escritos, mas também de documentos de natureza iconográfica e cinematográfica, ou mesmo objetos do cotidiano, elementos folclóricos, dentre muitos.

Os documentos são, pois, considerados elementos que registram contextos em materiais, textos, hieróglifos, vídeos, imagens estáticas, livros, arte, transcrições da oralidade, impressos oficiais e monumentos. Eles compõem um arcabouço de informações sobre o passado, dos quais podemos extrair, interpretar, analisar e relacionar, à luz do presente, visando a compreensão dos fatos e circunstâncias das sociedades, em seu recorte temporal. Assim, os documentos, como produtos das sociedades, assumem relevância devido à possibilidade de conexões com o passado ${ }^{13-15}$.

A partir de então, os historiadores-pesquisadores vêm ampliando seus horizontes, visto que documento é toda fonte de informação da qual seja possível extrair elementos sobre o passado humano. Dessa forma, vale ressaltar que não refletem a vivência concreta em dado recorte temporal e, por essa razão, a necessidade de examiná-los, criteriosamente, para torná-los compreensíveis, livres de distorções, de maneira a evitar interpretações e conclusões equivocadas do objeto de estudo e, assim, assegurar os melhores

Quadro 1. Síntese cronológica das fontes históricas. Natal, 2021.

\begin{tabular}{|cl|}
\hline Cronologia & \multicolumn{1}{c|}{ Fontes Históricas } \\
\hline Anterior ao séc. XIX & Hagiografia; relatos de viagens; biografias; imagens; objetos; diários; censos demográficos \\
\hline Século XIX & $\begin{array}{l}\text { Leis; atas; regulamentos; tratados; declarações de guerras; censos demográficos; } \\
\text { certidões de nascimento e de óbitos }\end{array}$ \\
1930 & Fatos; depoimentos; processos; correspondências; diários \\
1970 & $\begin{array}{l}\text { Testamentos; registros de propriedades; inventários; censo; documentos fiscais; lista de } \\
\text { preços }\end{array}$ \\
Após 1980 & $\begin{array}{l}\text { Fontes orais; programas de partidos; discursos; jornais; teatro; arquivos digitais; teses e } \\
\text { dissertações; artigos científicos, além de todos os anteriores }\end{array}$ \\
\hline
\end{tabular}

Fonte: Dados da pesquisa, 2021 
Quadro 2. Características dos documentos. Natal, 2021.

\begin{tabular}{|c|c|}
\hline Características & Descrição \\
\hline Organicidade & $\begin{array}{l}\text { Produzidos e acumulados em razão das funções e atividades desenvolvidas pelo órgão ou } \\
\text { entidade, o que os contextualiza no conjunto a que pertence. }\end{array}$ \\
\hline Unicidade & $\begin{array}{l}\text { Único no conjunto documental de que faz parte, ainda que existam cópias em grupos de } \\
\text { documentos; cada cópia é única em seu lugar. }\end{array}$ \\
\hline Confiabilidade & $\begin{array}{l}\text { Capacidade de sustentar os fatos que atestam; a veracidade de seu conteúdo; fidedignidade; } \\
\text { relaciona-se a sua produção. }\end{array}$ \\
\hline Autenticidade & Sem adulterações ou modificação; inalterado desde a sua produção. \\
\hline
\end{tabular}

Fonte: Arquivo Nacional, $2011^{20}$.

esclarecimentos. Ao realizar uma pesquisa documental, torna-se imprescindível a observância de características relacionadas aos documentos, como as disponíveis no Quadro 2.

Acerca das características dos documentos, vale complementar esses aspectos quanto: às circunstâncias de suas criações (próprias de um determinado contexto); à sua autenticidade (testemunhos fiéis de momentos); à heterogeneidade de conteúdo; e à multiplicidade da informação (globalidade contida no material) ${ }^{16,17}$. Por isso, os documentos - contemporâneos ou retrospectivos - podem ser empregados como método, fontes, técnicas e análise, sendo vital adequá-los às finalidades da pesquisa no tocante aos processos das informações, a escolha do material estudado, organização, análise e síntese.

A análise das características dos documentos não deve ser reputada a um procedimento meramente protocolar da pesquisa histórica. Sua realização desafiará o pesquisador-historiador a desenvolver habilidades e sagacidade para melhor explorar as potencialidades das fontes e a estabelecer suas relações com o contexto histórico investigado. $\mathrm{O}$ desenvolvimento dessa aptidão pode ser visto, também, sob perspectiva de melhor utilização do tempo empregado à pesquisa.

\section{Documentos: guarda, conservação, manuseio e cuidados}

A produção de documentos é contínua e, diante da variedade existente, muitos são os desafios enfrentados pelas instituições e depositários quanto à guarda e conservação. Da nossa vivência como pesquisadores-historiadores, podemos citar: catalogação das fontes históricas; espaços adequados à realização de pesquisas; manutenção da estrutura física das instituições; investimentos financeiros e tecnológicos; capacitação profissional; falta de mobiliário adequado, entre outros.

No Brasil, pode-se dizer que esses serviços foram estruturados após a instalação da família Real, em 1808, no Rio de Janeiro, tendo a criação e funcionamento do Arquivo Público Imperial $(1838)^{18}$ - hoje, Arquivo Nacional - e do Instituto Histórico e Geográfico Brasileiro (1838) ${ }^{19}$ como marcos e modelos para a ampliação de instituições análogas. Na atualidade, destacam-se as bibliotecas, os serviços de arquivos - públicos e privados -, os museus e os centros de documentação como os principais. Entretanto, não são os únicos responsáveis pela guarda dos documentos, embora se distingam quanto às classificações, objetivos, acervo e público-alvo ${ }^{14}$.

Sobre guarda e conservação, os arquivos digitais nos chamam a atenção acerca das garantias futuras, visto que as inovações tecnológicas, em sua maioria, são substitutivas às vigentes, podendo, assim, comprometer a localização e utilização desse material. Elencam-se, ainda, como possíveis desafios aos pesquisadores-historiadores: os elevados custos do maquinário (computadores, impressoras, softwares, antivírus, digitalização); a qualidade da internet; os ataques cibernéticos causados por vírus e hackers; a digitalização documental. Assim sendo, observa-se que a conservação geral de quaisquer documentos está diretamente relacionada à garantia do seu acesso e uso, devendo, para tal, estarem todos eles corretamente selecionados, identificados, classificados, armazenados e controlados em sua guarda, localização, manuseio e reutilização.

Para tanto, ambiciona-se que as instituições e depositários tenham condições de seguir algumas recomendações, a saber: a monitoração da temperatura e da umidade das áreas de pesquisa, trabalho e depósito; o manejo adequado quanto à luminosidade e à ventilação ambiental; o cumprimento de rotinas de higienização documental; o controle de roedores, insetos (traças, baratas, cupins, brocas) e microrganismos (fungos e bactérias); o armazenamento dos documentos de acordo às suas especificidades; e a utilização de mobiliário adequado aos diversos tipos de documentos 20,21 .

Como parte desse processo, o pesquisador-historiador deve contribuir para a conservação dos documentos, adotando as seguintes medidas: ter cautela no manuseio dos documentos; higienizar e secar as mãos antes e após o manejo; dispor de equipamentos de proteção individual (luvas de látex, máscaras, aventais, toucas e óculos de proteção); utilizar pincéis de cerdas; não utilizar fitas adesivas, marcadores de textos, materiais metálicos e nenhuma dobradura ou anotação para sinalização nos documentos; atentar para os cuidados, dependendo da procedência e do tipo de documento como fotografias, vídeos, peças e utensílios, obras de arte; não alimentar-se ou beber na área de tratamento documental ${ }^{20,21}$.

Tais considerações merecem ser apreciadas com maior aprofundamento, mas, por ora, atendem à finalidade de dar visibilidade aos desafios institucionais apontando elementos e 
conhecimentos técnicos concernentes ao mundo dos arquivos. Acredita-se que a conscientização sobre a importância do cuidado - guarda, conservação e manuseio - dos documentos contribuirá para aumentar a sobrevida dessas fontes históricas e, assim, a esperança de que estarão disponíveis às gerações futuras.

\section{Pesquisa histórica-documental aplicada à Enfermagem}

A expressividade das fontes históricas - textuais e não textuais - e suas múltiplas utilizações por pesquisadores-historiadores de variadas áreas pressupõem o emprego de técnicas e métodos específicos para cada desígnio, tornando-as, por essa razão, aplicáveis às pesquisas qualitativas e quantitativas. Dimensionase, portanto, quão vasto pode ser o debate, mas, por enquanto, tecer-se-ão algumas considerações sobre a pesquisa documental, pretendendo motivar discussões entre pesquisadores-historiadores e o despertar de novos interessados.

Como em toda pesquisa científica, a documental exige a elaboração do projeto em igual estrutura às demais; ou seja, contém introdução, delimitação do tema, revisão bibliográfica, justificativas, objetivos gerais e específicos, referencial teóricometodológico, instrumentos para coleta de dados, cronograma e referências ${ }^{4,8}$. Além disso, recomenda-se que seja elaborado em conformidade às diretrizes sobre pesquisas envolvendo seres humanos $^{22}$ e quanto à utilização de dados dos participantes ${ }^{23}$ Posteriormente, orienta-se cumprir o protocolo de sua submissão ao Comitê de Ética em Pesquisa.

O projeto de pesquisa é, então, uma necessidade singular e crucial, cuja finalidade é instrumentalizar o pesquisador-historiador a atingir seus propósitos por meio do planejamento sistemático de ações que almejem o desenvolvimento, o aprimoramento e a ampliação de seus conhecimentos sobre o objeto de estudo ${ }^{8}$. Em vista disso, a realização de qualquer tipo de pesquisa científica convive com ciclos dinâmicos e interligados, podendo ser comparada a um labor artesanal, composto pelas seguintes fases: exploratória (elaboração do projeto); trabalho de campo (levantamento bibliográfico, coleta de dados); e tratamento do material levantado (ordenação, classificação e análise) ${ }^{1,24}$.

Nas pesquisas documentais, o tratamento do material alçado tem por interesse a superação de incertezas e o enriquecimento da leitura, diante da necessidade de ultrapassar as aparências nele contidas, buscando-se a compreensão e a interpretação contextualizadas dos acontecimentos decorrentes da verificação prudente das informações. A execução desse processo confere nova representação ao documento, passando de primário (bruto) para secundário (interpretação do primeiro) ${ }^{25,26}$.

A consecução desse procedimento envolve três etapas: préanálise (seleção e organização dos documentos por meio da leitura flutuante e a constituição do corpus documental de acordo com as regras da exaustividade, representatividade, homogeneidade e pertinência); exploração do material (classificação, codificação ou categorização dos dados brutos situados por recorte, agregação ou numeração segundo características similares); e tratamento dos resultados obtidos e interpretações (validação e significação dos dados pelas inferências do pesquisador) ${ }^{25,27}$.

Legitimar as fontes documentais torna-se, pois, uma ação vita ao desenvolvimento de qualquer pesquisa. Nessa circunstância, quando se tratar de estudo histórico, com abordagem qualitativa, referente a um passado próximo, a possibilidade de realização de entrevistas, com atores que vivenciaram o acontecimento, é um valoroso recurso para balizar informações ${ }^{16}$.

Nesse sentido, a ratificação dos dados constitui-se em um grande desafio para os historiadores-pesquisadores, e sua operacionalização significa conferir qualidade e confiabilidade aos resultados da pesquisa. Dessarte, aos que desejarem publicações em periódicos científicos, a Red Equator, em parceria com a Organização Pan-Americana de Saúde (OPAS), e no empenho de favorecer o aperfeiçoamento dos manuscritos, elaborou guias, disponibilizando-os em vários idiomas, como o Consolidated criteria for reporting qualitative research (COREQ), recomendado aos estudos com abordagem qualitativa que realizam entrevistas ${ }^{28}$.

Da nossa vivência, referindo-se ao passado próximo, identificamos a utilização da pesquisa documental articulada à História Oral - temática ou de vida - como método ou técnica, com a finalidade de avaliar e analisar a fonte mediante a realização das críticas interna e externa das informações coletadas. Assim, vale o destaque de que pesquisas dessa natureza registram seu início na década de 1980 e são, em sua maioria, produtos de Teses e Dissertações vinculadas aos Programas de Pós-Graduação em Enfermagem, por meio dos grupos de pesquisa ${ }^{29,30}$. Tais grupos ampliaram-se a partir da década de 1990 e, apesar de hoje estarem presentes em todas as regiões brasileiras, concentram-se no Centro-Sul do país, com predominância às instituições públicas federais ${ }^{31}$, fenômeno similar à distribuição dos Programas de Pós-Graduação em Enfermagem ${ }^{7}$.

Tratam-se de grupos que possuem comprovada qualificação e produção acadêmica, formados por doutores, mestres e discentes (Pós-Graduação, Graduação e bolsistas) que motivam a organização, o desenvolvimento científico e a prática profissional competente. Nessa perspectiva, salienta-se que esses grupos vêm concorrendo, com elementos contextualizados sobre as relações sociais e as condições de trabalho da Enfermagem, à compreensão de suas implicações conexas à profissão.

\section{CONCLUSÃO E IMPLICAÇÕES PARA A PRÁTICA}

Cientes de que estas considerações não se encerram aqui, vale lembrar, aos interessados em adentrar o mundo das pesquisas históricas, que os acervos se organizam a partir de critérios temáticos. Por isso, assinalamos que o desenvolvimento exitoso da pesquisa implica vencer o desafio da identificação, localização e disponibilidade prévias desses serviços, assim como é primordial a leitura de estudos análogos. A adoção de cuidados simples, similares a esses, certamente se converterá em perspectivas positivas à pesquisa, ocasionando benefícios 
às realizações das atividades, previsão e controle de possíveis imprevistos e, principalmente, motivação e satisfação ao historiador-pesquisador.

Nossa trajetória como pesquisadores-historiadores em Enfermagem, nos oportunizou apreender que os melhores serviços de arquivo são aqueles que nos instrumentalizam com as informações tencionadas. Desse modo, a busca pelas melhores fontes torna-se um exercício da perseverança e disponibilidade, sendo indispensável realizá-la tantas vezes sejam necessárias à evolução da pesquisa, pois a "garimpagem" das fontes documentais pode não corresponder às expectativas e ao tempo do pesquisador-historiador. Tal possibilidade robustece a importância da elaboração do projeto de pesquisa - em particular no que toca ao cronograma -, visto que imprevistos são passíveis de ocorrer e comprometer o andamento da pesquisa.

Quando comparada a outras profissões, a sistematização do cuidado e do conhecimento aplicado à Enfermagem é considerada recente, tendo em Florence Nigthingale, no século XIX, com Notas sobre Enfermagem, o marco da publicação dos primeiros estudos. Sob esse aspecto, também sua história pode ser considerada recente, e com certeza foi por isso a Organização Mundial da Saúde (OMS), juntamente com entidades representativas da categoria, no intuito de enobrecer suas práticas e dar visibilidade aos seus profissionais, escolheu 2020 como Ano Internacional da Enfermagem, em referência ao bicentenário do nascimento de sua precursora. Por infelicidade, a crise sanitária mundial causada pela pandemia da Covid-19 ofuscou essa iniciativa, mas serviu para tornarem públicas fragilidades e necessidades de discussão sobre acesso à assistência à saúde, jornadas e condições de trabalho, remuneração, formação e qualificação dos profissionais de saúde, em todo o mundo.

Por fim, espera-se que esta reflexão contribua para a incipiente produção pertinente aos aspectos teóricosmetodológicos associados à pesquisa histórica desenvolvida pelos pesquisadores-historiadores de Enfermagem. Diante disso, ensejamos que sua efetivação se converta em fonte de consulta e em estímulos a novos estudos sobre a temática, de modo a acrescentar elementos indispensáveis à sistematização da história da Enfermagem. De antemão, deixamos o estímulo de que a pesquisa documental é um campo amplo e fértil, podendo o fenômeno ser estudado sob vários aspectos.

\section{CONTRIBUIÇÕES DOS AUTORES}

Desenho do estudo de reflexão. Djailson José Delgado Carlos. Levantamento de informações. Djailson José Delgado Carlos. Maria Lígia dos Reis Bellaguarda. Maria Itayra Padilha. Análise teórico-reflexiva. Djailson José Delgado Carlos. Maria Lígia dos Reis Bellaguarda. Maria Itayra Padilha.

Interpretação. Djailson José Delgado Carlos. Maria Lígia dos Reis Bellaguarda. Maria Itayra Padilha.

Redação e revisão crítica do manuscrito. Djailson José Delgado Carlos. Maria Lígia dos Reis Bellaguarda. Maria Itayra Padilha. Aprovação da versão final do artigo. Djailson José Delgado Carlos. Maria Lígia dos Reis Bellaguarda. Maria Itayra Padilha.
Responsabilidade por todos os aspectos do conteúdo e a integridade do artigo publicado. Djailson José Delgado Carlos. Maria Lígia dos Reis Bellaguarda. Maria Itayra Padilha.

\section{EDITOR ASSOCIADO}

\author{
Antônio José de Almeida Filho (D)
}

\section{EDITOR CIENTÍFICO}

\author{
Ivone Evangelista Cabral (iD
}

\section{REFERÊNCIAS}

1. Lundy KS. Historical research. In: Munhall PL, editor. Nursing research: a qualitative perspective. $5^{\text {a }}$ ed. Flórida (USA): Ed. Jones \& Bartlett Learning; 2012. p. 381-98.

2. Halbwachs MA. Memória coletiva. Tradução de Beatriz Sidou. $2^{2}$ ed. São Paulo: Ed. Centauro; 2013.

3. Burke P. A Escola de Annales (1929-1989): a revolução francesa da historiografia. $2^{\mathrm{a}}$ ed. São Paulo (SP): Editora UNESP; 2011.

4. Padilha MI, Borenstein MS, Bastiani J, Zytkuewisz GV, Lessman J. As fontes historiográficas em pauta: a história oral e a pesquisa documental. In: Borenstein M, Padilha MI, organizadores. Enfermagem em Santa Catarina: recortes de uma história - (1900-2011). Florianópolis (SC): Ed. Secco; 2011. p. 37-58

5. Lewenson S. Doing historical research. In: Lewenson SB, Herrmann EK, editors. Capturing nursing history. New York (USA): Ed. Springer Publishing Company; 2008. p. 25-44.

6. Aperibense PGGS, Silva CPG, Santos TCF, Almeida AJ Fo, Nelson $S$, Peres MAA. The uniform of nursing students: a strategy for the construction of professional identity (1950-1960). Texto Contexto Enferm. 2019;28:e20170593. http://dx.doi.org/10.1590/1980-265xtce-2017-0593.

7. Santos RMM, Santos AR, Sales AS, Pinto LLT, Vilela ABA, Yarid SD. Expansão da pós-graduação no Brasil e o processo de implantação do doutorado em Enfermagem e saúde no Sudoeste da Bahia. Enferm Actual Costa Rica. 2019;36:139-50. http://dx.doi.org/10.15517/revenf. v0i36.33647.

8. Barros JDA. O projeto de pesquisa em História: da escolha do tema ao quadro teórico. 10 ed. Petrópolis: Vozes; 2014.

9. Le Goff J. História e memória. $7^{\text {a }}$ ed. Campinas: Editora da UNICAMP; 2013.

10. Carneiro A, Barros A. Use of documents to narrate the history of organizations: reflections and experiences. Journal of Accounting and Organizations. 2017;30:14-23. http://dx.doi.org/10.11606/rco. v11i30.134408.

11. Hobsbawm E. Sobre História. Edição de bolso. São Paulo (SP): Companhia das Letras; 2013.

12. Cellard A. A análise documental. In: Poupart J, Deslauriers JP, Groulx LH, Laperrière A, Mayer R, Pires AP, organizadores. A pesquisa qualitativa: enfoques epistemológicos e metodológicos. $4^{a}$ ed. Petrópolis (RJ): Ed. Vozes; 2014. p. 295-316.

13. Aróstegui J. A pesquisa histórica: teoria e método. Bauru (SP): EDUSC; 2006.

14. Bellotto HL. Arquivos permanentes: tratamento documental. $4^{\text {a }}$ ed. Rio de Janeiro (RJ): Editora FGV; 2008.

15. Lakatos EM, Marconi MA. Fundamentos de metodologia científica. $9^{a}$ ed. Rio de Janeiro (RJ): Atlas; 2021.

16. Padilha MI, Bellaguarda MLR, Nelson S, Maia ARC, Costa R. The use of sources in historical research. Texto Contexto Enferm. 2017;26(4):e2760017. http://dx.doi.org/10.1590/0104-07072017002760017.

17. Alberti V. Manual História oral. $3^{\underline{a}}$ ed. Rio de Janeiro (RJ): Editora FGV; 2013. 
18. Wehling AO. IHGB e a fundação do Instituto Histórico de Petrópolis. $R$ IHGB. [Internet]. 2014; [citado 2021 jul 9]; 175(463):279-86. Disponível em: https://drive.google.com/file/d/OB1YEBXzhog3UYzdBSVM1OF95NjQ/ view?resourcekey=0-NzcADoEKgYfCtUKPm2ERKg

19. Paiva $\mathrm{H}$, Papali MA. $\mathrm{O}$ surgimento dos arquivos nacionais no ocidente. In: Anais do XXII Encontro Latino-Americano de Iniciação Científica, XVIII Encontro Latino-Americano de Pós-Graduação e VIII Encontro de Iniciação à Docência; 2018 out 25-26; Teresina, Paraíba, Brasil. Teresina: Universidade do Vale do Paraíba; 2018 [citado 2021 jul 9]. p. 1-6. [Internet]. Disponível em: http://www.inicepg.univap.br/cd/ INIC_2018/anais/arquivos/0095_0409_01.pdf

20. Arquivo Nacional (BR). Gestão de Documentos. Rio de Janeiro (RJ): Arquivo Nacional: 2011 [citado 2021 jul 9]. Disponível em: http://siga. arquivonacional.gov.br/images/cursos_capacitacao/Apostila_gestao documentos_2015.pdf

21. Arquivo Nacional (BR). Manual Técnico de Preservação e Conservação. Rio de Janeiro (RJ): Arquivo Nacional; 2011 [citado 2021 jul 9]. Disponível em: https://corregedoria.tjce.jus.br/wp-content/uploads/2016/02/ Manual-T\%C3\%A9cnico-de-Preserva\%C3\%A7\%C3\%A3o-eConserva\%C3\%A7\%C3\%A3o-de-Documentos-Extrajudiciais-.pdf

22. Resolução $n .-9466$, de 12 de dezembro de 2012 (BR). Dispõe sobre pesquisa envolvendo seres humanos. Diário Oficial da União [periódico na internet], Brasília (DF), 13 jun 2021 [citado 2021 jul 15]; Seção 1, p. 59. Disponível em: https://conselho.saude.gov.br/resolucoes/2012/ Reso466.pdf

23. Resolução n. 510 , de 7 de abril de 2016 (BR). Dispõe sobre as normas aplicáveis a pesquisas em Ciências Humanas e Sociais cujos procedimentos metodológicos envolvam a utilização de dados diretamente obtidos com os participantes ou de informações identificáveis ou que possam acarretar riscos maiores do que os existentes na vida cotidiana. Diário Oficial da União [periódico na internet], Brasília (DF), 7 abr 2016 [citado 2021jul 10]; Seção 1, p. 44-6. Disponível em: http://conselho.saude.gov.br/resolucoes/2016/ Res0510.pdf

24. Tappen R. Advanced nursing research. $2^{a}$ ed. Burlington Massachusetts (EUA): Jones \& Bartlett Publishers; 2015.

25. Bardin L. Análise de conteúdo. São Paulo: Edições 70; 2011.

26. Peres MAA, Aperibense PGGS, Bellaguarda MLR, Almeida DB, Santos FBO. Luchesi. Reconhecimento à Anna Justina Ferreira Nery: mulher e personalidade da história da Enfermagem. Esc Anna Nery Rev. Enferm. 2021;25(2):e2020020. http://dx.doi.org/10.1590/2177-9465EAN-2020-020207.

27. Minayo MCS. O desafio do conhecimento: pesquisa qualitativa em saúde. $12^{\mathrm{a}}$ ed. São Paulo: Hucitec; 2014.

28. Souza VR, Marziale MH, Silva GT, Nascimento PL. Translation and validation into Brazilian Portuguese and assessment of the COREQ checklist. Acta Paul Enferm. 2021;34:eAPE02631. http://dx.doi. org/10.37689/actaape/2021AO02631.

29. Teodósio SSCS, Silva ER, Padilha MI, Mazera MS, Borenstein MS. Ora history and documental investigation as a research itinerary in nursing: a bibliometric study (2000-2014). Esc Anna Nery. 2016;20(4):e20160087. http://dx.doi.org/10.5935/1414-8145.20160087.

30. Andrade SR, Schmitt MD, Storck BC, Piccoli T, Ruoff AB. Documentary analysis in nursing theses: data collection Techniques and research methods. Cogitare Enferm. 2018;1(23):e53598. http://dx.doi.org/10.5380/ ce.v23i1.53598.

31. Conselho Nacional de Pesquisa. Diretórios dos Grupos de Pesquisa [Internet]. Brasília: CNPq; 2021 [citado 2021 jul 16]. Disponível em: http://lattes.cnpq.br/web/dgp/home

a Nessa reflexão, assim nos referiremos àqueles que, mesmo não tendo formação em História, mas ao descobrirem o universo da pesquisa histórica, reconhecem sua importância e se veem motivados e/ou apaixonados a realizá-las. 